\title{
Publisher Correction: Radioactive drugs emerge from the shadows to storm the market
}

Elie Dolgin

Correction to: Nature Biotechnology https://doi.org/10.1038/nbt1218-1125, published online 6 December 2018.

In the version of this article initially published, Betalutin was described as directing a radioisotope to CD45-expressing B cells; in fact, it directs it to CD37-expressing B cells. The error has been corrected in the HTML and PDF versions of the article. 